Article

\title{
Encapsulation Effect on the In Vitro Bioaccessibility of Sacha Inchi Oil (Plukenetia volubilis L.) by Soft Capsules Composed of Gelatin and Cactus Mucilage Biopolymers
}

\author{
María Carolina Otálora ${ }^{1, *} \mathbb{*}$, Robinson Camelo ${ }^{2} \mathbb{D}$, Andrea Wilches-Torres ${ }^{1}$, \\ Agobardo Cárdenas-Chaparro ${ }^{2}$ (D) and Jovanny A. Gómez Castaño ${ }^{2, *(D)}$ \\ 1 Grupo de Investigación en Ciencias Básicas (NÚCLEO), Facultad de Ciencias e Ingeniería, \\ Universidad de Boyacá, 150001 Tunja, Boyacá, Colombia; andreawilches@uniboyaca.edu.co \\ 2 Grupo Química-Física Molecular y Modelamiento Computacional (QUIMOL), Facultad de Ciencias, \\ Universidad Pedagógica y Tecnológica de Colombia (UPTC), 150001 Tunja, Boyacá, Colombia; \\ luis.camelo@uptc.edu.co (R.C.); agobardo.cardenas01@uptc.edu.co (A.C.-C.) \\ * Correspondence: marotalora@uniboyaca.edu.co (M.C.O.); jovanny.gomez@uptc.edu.co (J.A.G.C.)
}

Received: 30 July 2020; Accepted: 23 August 2020; Published: 2 September 2020

\begin{abstract}
Sacha inchi (Plukenetia volubilis L.) seed oil is a rich source of polyunsaturated fatty acids (PUFAs) that are beneficial for human health, whose nutritional efficacy is limited because of its low water solubility and labile bioaccessibility (compositional integrity). In this work, the encapsulation effect, using blended softgels of gelatin $(\mathrm{G})$ and cactus mucilage $(\mathrm{CM})$ biopolymers, on the PUFAs' bioaccessibility of $P$. volubilis seed oil was evaluated during in vitro simulated digestive processes (mouth, gastric, and intestinal). Gas chromatography-mass spectrometry (GC-MS) and gas chromatography with a flame ionization detector (GC-FID) were used for determining the chemical composition of $P$. volubilis seed oil both before and after in vitro digestion. The most abundant compounds in the undigested samples were $\alpha$-linolenic, linoleic, and oleic acids with 59.23, 33.46, and $0.57(\mathrm{~g} / 100 \mathrm{~g})$, respectively. The bioaccessibility of $\alpha$-linolenic, linoleic, and oleic acid was found to be $1.70 \%, 1.46 \%$, and $35.8 \%$, respectively, along with the presence of some oxidation products. $\mathrm{G} / \mathrm{CM}$ soft capsules are capable of limiting the in vitro bioaccessibility of PUFAs because of the low mucilage ratio in their matrix, which influences the enzymatic hydrolysis of gelatin, thus increasing the release of the polyunsaturated content during the simulated digestion.
\end{abstract}

Keywords: softgels; mucilage; biopolymers; in vitro digestion; bioaccessibility

\section{Introduction}

Sacha inchi (Plukenetia volubilis L.) is a plant belonging to the Euphorbiaceae family that grows in the Amazon rainforest in Northeastern Peru and Northwestern Brazil. It has aroused interest in the food industry because of the high quantity and quality of the edible oils contained in its seeds. Its fruit consists of a star-shaped capsule that is approximately $3-5 \mathrm{~cm}$ in size, and normally contains between four and six dark brown edible oval seeds that are 1.5-2 $\mathrm{cm}$ in size [1]. The seeds of this plant are an excellent source of edible oil (41-54\%). This oil contains lipids (35-60\%), free fatty acids $(1.2 \%)$, and phospholipids (0.8\%) [2]. The high nutritional value of sacha inchi oil is due to its high polyunsaturated fatty acid (PUFA) and monounsaturated fatty acid (MUFA) content, which varies between $77.5 \%$ and $84.4 \%$, and $8.4 \%$ and $13.2 \%$, respectively [2-4]. $\alpha$-Linolenic acid (ALA; C18:3, $\omega-3$ ) is the major fatty acid (47-51\%), followed by linoleic acid (LA; C18:2, $\omega-6,34-37 \%$ ) and oleic acid $(\omega-9,9-10 \%)$ [2]. These fatty acids are considered beneficial because of their antioxidant, antithrombotic, 
antidyslipidemic, and anticancer effects [5-7]. Although PUFAs are beneficial, they are very sensitive to oxidative damage when exposed to oxygen, and are affected by heat, light, and humidity [8]. Therefore, it is essential to establish adequate systems for the transport and encapsulation of fatty acids, while maintaining their nutritional properties until they are released within the body.

Encapsulation with hydrocolloid biopolymers is an effective and widely used technique in the food industry in order to protect dietary supplements against oxidation and loss of nutritional value. Its effectiveness is as a result of the hermeticity of its walls and the safe supply of bioactive compounds, due to its rapid disintegration in biological fluids at body temperature $[9,10]$. This characteristic makes soft capsules (or softgels) one of the most widely used encapsulation methods because of their safe and nutritionally-accepted means of delivering aqueous liquid or semi-solid dosage formulations. Although there are several studies on the encapsulation of omega-3 fatty acids using different techniques [11-14], the use of soft capsules for the encapsulation of polyunsaturated fatty acids in scientific studies is scarce $[15,16]$.

Softgels are generally manufactured with animal-derived gelatin $(G)$, water, non-volatile plasticizers, and minor additives such as opacifiers and dyes $[17,18]$. The choice of $G$ as a traditional material in the walls of softgels is related to its biodegradable nature and its ability to form thermo-responsive hydrogels $[19,20]$. An emerging trend in the food industry has recently sought to partially or completely replace $G$ with other non-animal natural hydrocolloids. This has allowed plant mucilage to emerge as an attractive structural biopolymer alternative to soft capsules [21]. The mucilage extracted from the cladodes of Opuntia ficus-indica is a heteropolysaccharide matrix that has proven to be a suitable natural structuring material in soft capsules because of its high fiber content and desirable functional properties [22-24].

Bioaccessibility is defined as the amount of a bioactive compound that can cross the intestinal barrier as a result of its release from the matrix by the action of digestive enzymes [25]. Therefore, the stability of the encapsulated polyunsaturated fatty acids that are released into the gastrointestinal tract and are available for intestinal absorption is directly related to the biocompatibility and biodegradability rates of the capsule matrix [26]. As a result, the behavior of the capsule structure in relation to changes in $\mathrm{pH}$ and the presence of digestive enzymes and bile salts is an important factor that should be properly evaluated. This makes in vitro methods that simulate gastrointestinal media particularly advantageous for the quantification of the biocompatibility and biodegradability of soft capsules containing such nutrients. The advantages of in vitro methods include speed, cost efficiency, and a lack of ethical restrictions when compared to in vivo methods [27]. The use of in vitro conditions provides the opportunity to evaluate the suitability of a matrix's ability to carry functional compounds of interest for the food and pharmaceutical industries. The bioaccessibility of polyunsaturated fatty acids has been evaluated using in vitro models in different studies [28,29].

The primary interest of this study was to determine the effect of gelatin/cactus mucilage as a softgel wall material in the in vitro digestion of encapsulated sacha inchi oil (SIO). The bioaccessibility analysis was performed using a comparative study that involved the quantification and identification of bioactive compounds using gas chromatography with a mass spectrometry (MS) detector and a flame ionization (FID) detector. The quantification was performed both before and after different laboratory-scale digestion processes. To the best of our knowledge, this study is the first evaluation of soft capsule wall matrices in the bioaccessibility of edible SIOs, which may be a topic of relevant interest to the food supplement industry.

\section{Materials and Methods}

\subsection{Materials and Reagent}

Sacha inchi fruits were supplied by local farmers in Miraflores (Boyacá, Colombia). The seeds were selected manually by discarding those that presented physical damage. They were packaged in polyethylene bags and stored at $18{ }^{\circ} \mathrm{C}$ until use. Cactus mucilage (CM) was extracted from the 
cladodes of Opuntia ficus-indica provided by local farmers in Duitama (Boyacá, Colombia), following the methodology reported by Quinzio et al. [30], and were used without further purification. Food grade gelatin (Type B, bloom strength 285, pI 4.2-6.5, Mw 40,000-50,000 Da, and 99\% purity) was provided by Gelco (Medellín, Antioquia, Colombia). Glycerol was provided by Merck (Darmstadt, Germany) for use as a plasticizer. Commercial samples of digestive enzymes and bile salts ( $\alpha$-amylase, pepsin from porcine gastric mucosa, and pancreatin from porcine pancreas) were obtained from Sigma-Aldrich (Auckland, New Zealand).

\subsection{Sacha Inchi Oil (SIO) Extraction}

The SIO extraction was performed using the Soxhlet methodology with chloroform as a solvent. Soxhlet extraction was selected as the most conventional, economical, and easiest process to implement. To maximize the SIO extraction, approximately $15 \mathrm{~g}$ of seed material was ground in an analytical mill (IKA A11 basic S1). Then, $1 \mathrm{~g}$ of seed sample was placed in a cellulose cartridge $(33 \times 80 \mathrm{~mm})$ for extraction using a Soxhlet extractor SER 148/3 Velp Scientifica (Usmate Velate, Italy) for $1.5 \mathrm{~h}$ with $60 \mathrm{~mL}$ of solvent.

\subsection{Characterization Sacha Inchi Oil}

\subsubsection{Fatty Acid Identification with Gas Chromatography Coupled to Mass Spectrometry (GC-MS)}

The chemical composition of the SIO sample was determined by gas chromatography coupled to mass spectrometry (GC/MS) using a 6890 N GC-MS instrument (Agilent Technologies Inc., Palo Alto, CA, USA) coupled to an Agilent $5973 \mathrm{~N}$ inert mass selective (IMS) detector. A capillary column DB-1MS ( $30 \mathrm{~m} \times 0.25 \mathrm{~mm}$ ID with $0.25 \mu \mathrm{m}$ film thickness) was employed for the analysis. The elution program started at a temperature of $70^{\circ} \mathrm{C}$, held for $2 \mathrm{~min}$, and then increased to $320^{\circ} \mathrm{C}$ at a speed of $8^{\circ} \mathrm{C} / \mathrm{min}$ and was held for $29 \mathrm{~min}$. Both the IMS detector and the injector port temperatures were 320 and $250^{\circ} \mathrm{C}$, respectively. The injection volume used was $3.0 \mu \mathrm{L}$, and helium was used as the carrier gas at a flow rate of $1 \mathrm{~mL} / \mathrm{min}$ in a splitless mode. The components were identified using a commercial library higher than 85\% (WileyW9N08, Mass Spectral Database of the National Institute of Standards and Technology (NIST)).

\subsubsection{Fatty Acid Profile with Gas Chromatography with a Flame Ionization Detector (GC-FID)}

The SIO sample was also analyzed using a 6890 N GC-FID instrument (Agilent Technologies Inc.). A capillary column DB-225 (60 m $\times 0.25 \mathrm{~mm}$ ID with $0.25 \mu \mathrm{m}$ film thickness) was employed for the analysis. The elution program started at a temperature of $75^{\circ} \mathrm{C}$ and increased to $220^{\circ} \mathrm{C}$ at a speed of $5{ }^{\circ} \mathrm{C} / \mathrm{min}$ for $50 \mathrm{~min}$. Both the detector and injector port temperatures were 220 and $250{ }^{\circ} \mathrm{C}$, respectively. The injection volume used was $0.2 \mu \mathrm{L}$, and helium was used as the carrier gas at a flow rate of $1 \mathrm{~mL} / \mathrm{min}$ in a 100:1 split mode.

\subsection{Soft Capsule Preparation with SIO Inclusion}

The soft capsule design was developed according to the method reported by Camelo et al. [21]. $\mathrm{CM}(1.0 \mathrm{~g})$ and food grade $\mathrm{G}(21.0 \mathrm{~g})$ were separately dissolved in $100 \mathrm{~mL}$ of distilled water at $18^{\circ} \mathrm{C}$ and $40^{\circ} \mathrm{C}$ for $2 \mathrm{~h}$ and $30 \mathrm{~min}$, respectively. Both solutions were constantly stirred at $300 \mathrm{rpm}$ using a magnetic stirrer (C-MAG HS 7S000, IKA, Staufen im Breisgau, Germany) in order to ensure complete solubilization. Afterwards, the gelatin solution was mixed separately with glycerol (Gly) at a concentration of $15 \%(w / v)$ at $60^{\circ} \mathrm{C}$ for $2 \mathrm{~h}$ to remove residual air bubbles and to obtain a homogeneous solution. The ratio of $\mathrm{G} / \mathrm{CM}(3: 1 \mathrm{w} / \mathrm{w})$ was homogenized at room temperature for $1 \mathrm{~h}$ under constant magnetic stirring. The biopolymer solution was poured into an elliptically-shaped mold ( $22 \mathrm{~mm}$ length and $11 \mathrm{~mm}$ diameter) and dried in a Memmert UM 400 drying oven (Schwabach, Germany) at $25^{\circ} \mathrm{C}$ with a relative humidity of $40 \%$ for $1 \mathrm{~h}$. Subsequently, $2 \mathrm{~mL}$ of sacha inchi oil was injected into the 
formed soft capsule. The syringe hole in the capsule was then sealed by carefully applying heat using a small hot spatula.

\subsection{Fatty Acids' Polyunsaturated Bioaccessibility}

The encapsulated oil was submitted to an in vitro digestion process using mouth, gastric, and intestinal simulation. This method was implemented as described by Pacheco et al. [31]. To simulate mouth digestion, $5 \mathrm{~g}$ of soft capsules were weighed and added to $9 \mathrm{~mL}$ of simulated saliva $(1.59 \mathrm{mM}$ $\mathrm{CaCl}_{2}, 21.1 \mathrm{mM} \mathrm{KCl}, 14.4 \mathrm{mM} \mathrm{NaHCO}_{3}, 0.2 \mathrm{mM} \mathrm{MgCl}_{2}, \mathrm{pH}$ adjusted to 7.0 using $1.0 \mathrm{~N} \mathrm{HCl}$, and the $\alpha$-amylase enzyme). This mixture was incubated in a Schutzart DIN 60529-IP 20 shaking water bath (Memmert, Germany) for $5 \mathrm{~min}$ at $37^{\circ} \mathrm{C}$, and agitated at $185 \mathrm{rpm}$. Gastric digestion was then initiated by adding $36 \mathrm{~mL}$ of pepsin solution $(25 \mathrm{mg} / \mathrm{mL}$ in $0.02 \mathrm{~N} \mathrm{HCl}$ ) to the samples. The mixture's $\mathrm{pH}$ was adjusted to 2.0 using $1.0 \mathrm{~N} \mathrm{HCl}$, and was incubated while continuously shaking at $130 \mathrm{rpm}$ at $37^{\circ} \mathrm{C}$ for $60 \mathrm{~min}$. To simulate intestinal digestion, the gastric-digested mixture's $\mathrm{pH}$ was adjusted to 6.0 using $1 \mathrm{M} \mathrm{NaHCO}_{3}$. Afterwards, $0.25 \mathrm{~mL}$ of pancreatin solution $(2 \mathrm{~g} / \mathrm{L})$ and biliary salts $(12 \mathrm{~g} / \mathrm{L})$ dissolved in aqueous $0.1 \mathrm{M} \mathrm{NaHCO}_{3}$ were added and then the mixture was incubated at $37^{\circ} \mathrm{C}$ for 120 min while constantly stirring at $45 \mathrm{rpm}$.

After intestinal digestion, the samples were immediately centrifuged at $5000 \mathrm{rpm}$ for $10 \mathrm{~min}$. The centrifuged samples were separated into two layers: an opaque sediment layer at the bottom, and a thin oily layer at the top. The oily layer was centrifuged again at $4000 \mathrm{rpm}$ for $3 \mathrm{~min}$ and filtered using a Millipore membrane $(0.45 \mu \mathrm{m})$, and then analyzed for its polyunsaturated fatty acid content and composition using GC-FID and GC-MS. The percentage of bioaccessibility was calculated using this equation:

$$
\text { Bioaccessibility }(\%)=\frac{(\text { Content of fatty acids polyunsaturated present in the digestion product })}{(\text { Content of fatty acids polyunsaturated present in the encapsulted matrix })} \times 100
$$

\section{Results}

\subsection{Characterization of Sacha Inchi Oil}

\subsubsection{Fatty Acid Identification with Gas Chromatography Coupled to Mass Spectrometry (GC-MS)}

As shown in the GC-MS chromatograms in Figure 1, the fatty acid profiles revealed 13 main chemical constituents in the SIO sample prior to encapsulation. The peaks numbered 1, 2, and 3 in the oil, eluted at retention times of $31.34,33.15$, and $33.19 \mathrm{~min}$, were identified as hexadecanoic acid methyl ester, 9,12-octadecadienoic acid methyl ester, and (Z,Z,Z)-9,12,15-octadecatrienoic acid methyl ester, respectively. This demonstrates that the oil is a rich source of polyunsaturated fatty acid. Peak number 4 in the chromatograms, eluted at a retention time of $33.52 \mathrm{~min}$, was identified as (Z)-11-octadecenoic acid methyl ester and octadecenoic acid methyl ester. The peaks numbered 5, 6, 7, 8 , and 9 were observed in the oil eluted at times of 33.52, 36.91, 37.68, 38.41, and $39.11 \mathrm{~min}$, respectively, and were identified as eicosane. In the sample, the compounds hexadecane (peak number 10), 1,4-phthalazinedione 2,3 dihydro-6-nitro (peak number 11), cyclotrisiloxane hexamethyl (peak number 12), and 5-methyl-2-phenylindolizine (peak number 13) were eluted at retention times of 39.79, 40.45, 41.08 , and $41.74 \mathrm{~min}$, respectively. 


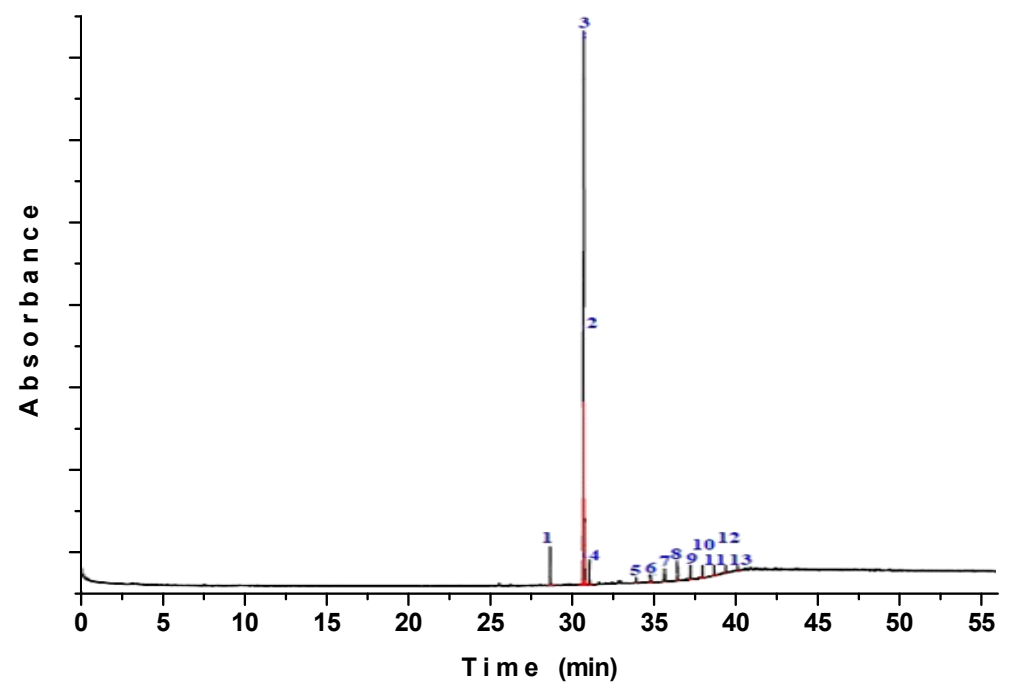

Figure 1. GC-MS chromatograms of sacha inchi oil before the simulated gastrointestinal digestion.

3.1.2. Fatty Acid Profile with Gas Chromatography with a Flame Ionization Detector (GC-FID)

The fatty acid contents analyzed by GC-FID in the unencapsuslated SIO sample (i.e., prior to encapsulation) are shown in Table 1. The presence of $\alpha$-linolenic (C18:3 $\omega-3)$, linoleic (C18:2 $\omega-6)$, palmitic (C16:0), stearic (C18:0), and oleic (C18:1 $\omega-9)$ acids, in decreasing order of abundance, indicated a rich source of polyunsaturated fatty acids. These values agreed with the results of Chirinos et al. [3] and Gutiérrez et al. [32]. The content of $\omega-3(59.23 \mathrm{~g} / 100 \mathrm{~g})$ is important and desirable because of its contribution to preventing several diseases such as obesity, diabetes, allergies, Alzheimer's, and coronary and neurodegenerative diseases [33]. The $\omega-6 / \omega-3$ ratio of 0.56 has many health and nutritional benefits, such as the reduction of chronic diseases, and in cardiovascular and hypertension disease prevention $[34,35]$. The low ratio of linoleic/ $\alpha$-linolenic is similar to the results obtained in both irradiated and non-irradiated sacha inchi oils [32].

Table 1. Fatty acid composition $(\mathrm{g} / 100 \mathrm{~g})$ of sacha inchi oil before the simulated gastrointestinal digestion.

\begin{tabular}{cc}
\hline Fatty Acid & g/100 g-Sample \\
\hline$\alpha$-Linolenic $(\mathrm{C} 18: 3 \omega-3)$ & 59.23 \\
Linoleic (C18:2 $\omega-6)$ & 33.46 \\
Oleic (C18:1 $\omega-9)$ & 0.57 \\
Stearic (C18:0) & 2.66 \\
Palmitic (C16:0) & 4.07 \\
\hline
\end{tabular}

\subsection{Chemical Content of Encapsulated SIO after Simulated In-Vitro Digestion}

In order to study the impact of soft capsules on the bioaccessibility of the fatty acids, the encapsulated sacha inchi oil was subjected to in vitro digestion (i.e., mouth-gastric-intestinal media simulation), and its chemical content was analyzed using GC-MS and GC-FID spectrometry.

\subsubsection{Products Derived from the Degradation of Polyunsaturated Fatty Acids after In Vitro Digestion}

The chromatogram profile of the main SIO compounds and their degradation by-products using GC-MS showed a maximum of 17 chemical constituents, as displayed in Figure 2. No peak attributable to 9,12-octadecadienoic acid methyl ester was detected in the chromatograms of the encapsulated oil after digestion, and therefore its bioaccessibility was considered negligible. Conversely, the presence of $(Z, Z, Z)-9,12,15$-octadecatrienoic acid methyl ester was detected before and after in vitro digestion in peaks number 3 and 13, which were eluted at a retention time of 33.20 and $32.06 \mathrm{~min}$, respectively. The presence of this fatty acid was detected in the chromatograms of the encapsulated oil after 
digestion in a $43.96 \%$ peak area, making its bioaccessibility considerably significant. The presence of peaks with different retention times was also evidenced. For instance, 10,13-octadecadienoic acid methyl ester was identified as a degradation by-product of 9,12-octadecadienoic acid methyl ester [36], along with derivatives such as propanal, alcoholic amines, and aromatic compounds. All were related as by-products of simulated gastrointestinal digestion, demonstrating a low bioaccessibility of the encapsulated oil.

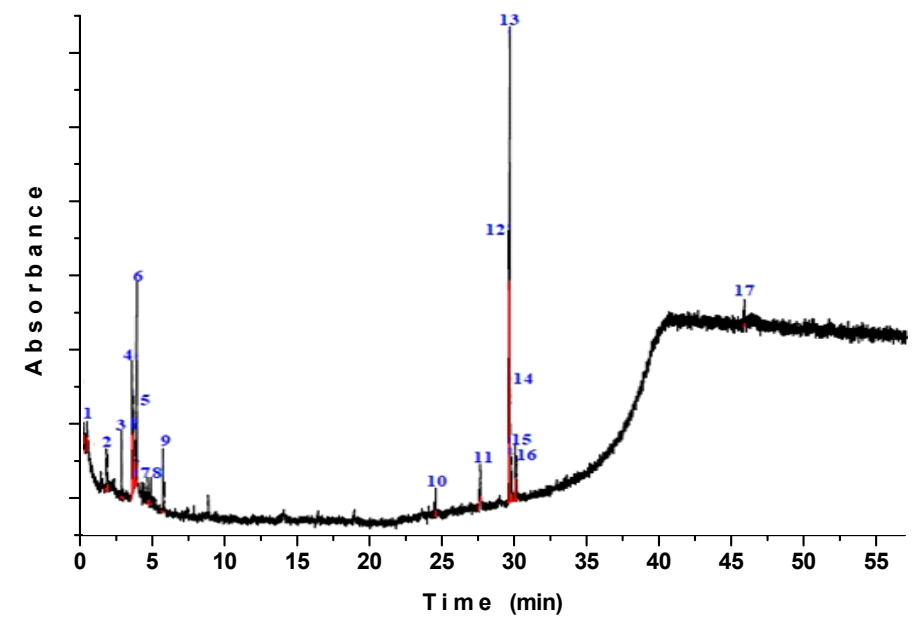

Figure 2. GC-MS chromatograms of sacha inchi oil after the simulated gastrointestinal digestion. Abbreviations: (1) Ethanol 2-(2-methoxyethoxy); (2) 3-[2-Diethylaminoethyl]-2,4-pentanedione; (3) Diethyl carbamoyl t-butoxy sulfide; (4) Ethane 1,2-bis(methylthio); (5) Ethane 1,2-bis(methylthio); (6) Cyclotetrasiloxane octamethyl; (7) Cycloserine; (8) 1-Propanol 2-amino; (9) 2-Pentanamine $N$-(1-methylbutyl); (10) $n$-Hexylmethylamine; (11) Methylpent-4-enylamine; (12) 10,13-Octadecadienoic acid methyl ester; (13) (Z,Z,Z)-9,12,15-Octadecatrienoic acid, methyl ester; (14) Epinephrine; (15) 1-Octanamine N-methyl; (16) 2-Amino-1-(o-hydroxyphenyl)propane; (17) Tetrasiloxane, decamethyl.

\subsubsection{Fatty Acid Content under the Simulated In Vitro Digestion}

The relative concentration of the encapsulated fatty acids before and after the simulated gastrointestinal digestion, determined using GC-FID spectrometry, is shown in Figure 3. It was found that the bioaccessibility of the $\alpha$-linolenic, linoleic, and oleic polyunsaturated fatty acids was $1.70 \%, 1.46 \%$, and $35.8 \%$ respectively, while the saturated stearic and palmitic acids presented bioaccessibility values of $2.26 \%$ and $1.72 \%$, respectively.

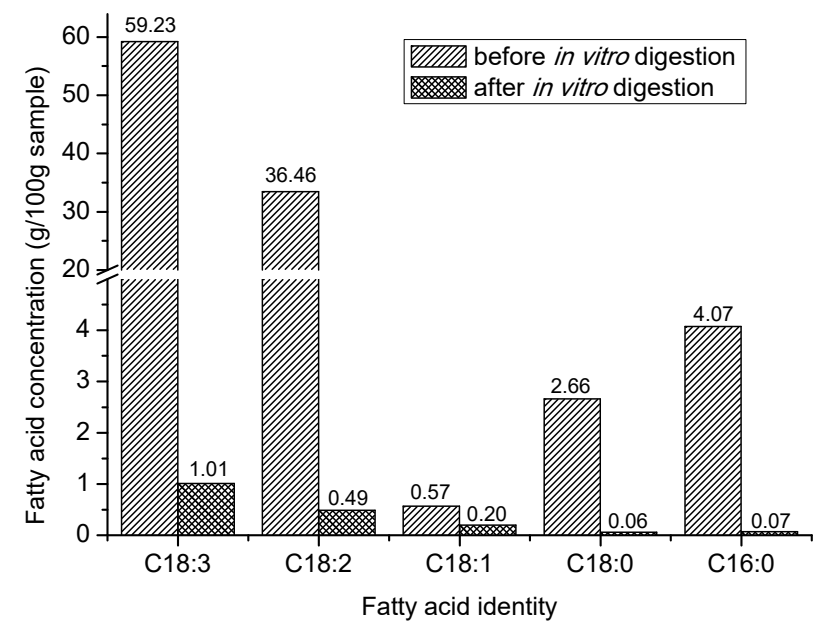

Figure 3. Relative concentration of fatty acids in sacha inchi oil (SIO) samples before and after the simulated gastrointestinal digestion. 


\section{Discussion}

As seen in Figure 3, during the digestion of the SIO encapsulated in G/CM softgels, there was a significant decrease in the content of the two most abundant PUFAs (i.e., $\alpha$-linolenic and linoleic acid content), which entailed a reduction in the nutritional and functional value of this natural oil. As can be inferred by comparing the GC-MS chromatograms of the SIO before and after in vitro digestion (Figures 2 and 3), the amounts of unsaturated fatty acids originally present in the SIO stimulated a higher generation of oxidation by-products during digestion [28]. Similar results were reported by Nieva-Echevarría, Goicoechea, and Guillén [37] during the in vitro gastrointestinal digestion of flaxseed oil. The amount of non-encapsulated oil (i.e., the oil that remained on the surface of the capsule) may also have affected the stability of the bioactive compound. In other words, the oil that was present at the surface of the capsule might have undergone oxidation and thereby affected the oxidative stability of the sample [38]. Alpizar-Reyes et al. [39] observed a similar situation when sesame seed oil was microencapsulated with tamarind seed mucilage.

Compared with the free sacha inchi oil [40], during in vitro digestion, the soft capsules showed a low protection of the encapsulated PUFAs against gastric conditions because of the nature of the wall materials and the G/CM ratio in the matrix. This behavior was associated with the intermolecular interactions between the functional groups of $\mathrm{CM}$ combined with $\mathrm{G}$, which gradually disappeared as a result of the repulsion forces of the biopolymers [21,41,42], as well as the rapid degradation of the gelatin by the proteolytic enzymes present in the stomach [20], which reduced the barrier properties of the matrix. This was insufficient at protecting the oil against oxidation, and in turn affected the porosity of the biopolymer matrix and the oil release rate during in vitro digestion. Furthermore, the low amount of CM hydrocolloid in the soft capsule allowed for the degradation and facilitation of the enzymatic hydrolysis of $G$ under gastric conditions [40].

These results seem to contradict the results of other published studies. Cortés-Camargo et al. [43] found that there was a delayed release of lemon essential oil microencapsulated using mesquite gum-chia mucilage mixtures. Papillo et al. [44] reported a high in vitro bioaccessibility of curcuminoids that were microencapsulated using gum arabic and maltodextrins as encapsulating agents. Da Silva Stefani et al. [45] reported a good bioavailability of nanoencapsulated linseed oil using chia seed mucilage as a structuring material. Jannasari et al. [42] studied the microencapsulation of vitamin D using gelatin and cress seed mucilage, and found release rates in the gastric and intestinal media of $28 \%$ and $70 \%$, respectively. In addition, Barrow et al. [46] reported a high bioavailability of omega-3 fish oil microencapsulated using the technique of complex coacervation (140-180 mg EPA/DHA/g powder) in contrast with softgel capsules (data not shown). These results suggest that the G/CM matrix is not an encapsulating biopolymer that is sufficiently resistant to gastric conditions, thus reducing the bioaccessibility of the bioactive compounds carried by G/CM softgels.

\section{Conclusions}

In this work, oil samples extracted from sacha inchi seeds were encapsulated in softgels composed of gelatin $(\mathrm{G})$ and cactus mucilage $(\mathrm{CM})$ biopolymers, and then exposed to simulated gastric conditions. The nutritional composition of the oil samples was evaluated before and after in vitro digestion by means of GC-MS and GC-FID spectrometry. In this way, the protective capacity of the contents of sacha inchi oil offered by the G/CM biopolymeric wall of the softgel against digestive processes was evaluated.

$\alpha$-Linolenic (C18:3 $\omega-3)$, linoleic (C18:2 $\omega-6)$, oleic (C18:1 $\omega-9)$, stearic (C18:0), and palmitic (C16:0) acids were the main fatty acids present in the non-encapsulated sacha inchi oil. It was found that the content of polyunsaturated fatty acids (PUFAs), especially $\alpha$-linolenic (C18: $3 \omega-3)$ and linoleic (C18: $2 \omega-6)$, carried by the G/CM softgels, decreased significantly during in vitro digestion (bioaccessibility equal to $1.70 \%$ or $1.46 \%$, respectively), which revealed a reduction in the nutritional value of the encapsulated oil after undergoing gastric processes. The low protective capacity of the 
$\mathrm{G} / \mathrm{CM}$ wall material was attributed to the low concentration of the $\mathrm{CM}$ hydrocolloid, which left the gelatin biopolymer exposed to enzymatic hydrolysis.

Although the bioaccessibility of the PUFAs obtained was relatively low, we believe that the use of a mixture of proteins (gelatin) and heteropolysaccharides (cactus mucilage) for the manufacture of microcapsules can act as a suitable delivery system for the incorporation of other bioactive compounds within acidic food matrices before being subjected to digestive processes, for example, by encapsulating functional agents and subsequent release (by shacking) in media such as fruit juices or dairy drinks. This result will undoubtedly be interesting for certain applications in the food and pharmaceutical industries.

Author Contributions: Data curation, R.C. and A.C.-C.; formal analysis, J.A.G.C. and M.C.O.; investigation, A.W.-T. and M.C.O.; project administration, M.C.O.; writing (original draft preparation), M.C.O.; writing (review and editing), J.A.G.C. and M.C.O. All authors have read and agreed to the published version of the manuscript.

Funding: This work was funded by the Universidad de Boyacá and the Universidad Pedagógica y Tecnológica de Colombia through the interinstitutional Project SGI 2384 of the Vicerrectoría de Investigaciones of the Universidad Pedagógica y Tecnológica de Colombia.

Conflicts of Interest: The authors declare that there is no conflict of interest.

\section{References}

1. Fu, Q.; Niu, L.; Zhang, Q.; Pan, B.Z.; He, H.; Xu, Z.F. Benzyladenine treatment promotes floral feminization and fruiting in a promising oilseed crop Plukenetia volubilis. Ind Crop. Prod. 2014, 59, 295-298. [CrossRef]

2. Gutiérrez, L.F.; Rosada, L.M.; Jiménez, A. Chemical composition of Sacha Inchi (Plukenietia volúbilis L.) seeds and characterisation of their lipid fraction. Grasas y Aceites 2011, 62, 76-83. [CrossRef]

3. Chirinos, R.; Zuloeta, G.; Pedreschi, R.; Mignolet, E.; Larondelle, Y.; Campos, D. Sacha inchi (Plukenetia volubilis): A seed source of polyunsaturated fatty acids, tocopherols, phytosterols, phenolic compounds and antioxidant capacity. Food Chem. 2013, 141, 1732-1739. [CrossRef] [PubMed]

4. Maurer, N.E.; Hatta-Sakoda, B.; Pascual-Chagman, G.; Rodriguez-Saona, L.E. Characterisation and authentication of a novel vegetable source of omega-3 fatty acids, Sacha Inchi (Plukenetia volubilis L.) oil. Food Chem. 2012, 134, 1173-1180. [CrossRef]

5. Kumar, B.; Smita, K.; Sánchez, E.; Stael, C.; Cumbal, L. Andean Sacha Inchi (Plukenetia volubilis L.) shell biomass as new biosorbents for $\mathrm{Pb}^{2+}$ and $\mathrm{Cu}^{2+}$ ions. Ecol. Eng. 2016, 93, 152-158. [CrossRef]

6. Garmendia, F.; Pando, R.; Ronceros, G. Effect of Sacha Inchi oil (Plukenetia volúbilis L.) on the lipid profile of patients with hyperlipoproteinemia. Rev. Peru. Med. Exp. Salud Publica 2011, 28, 628-632. [CrossRef]

7. Gonzalez-Aspajo, G.; Belkhelfa, H.; Haddioui-Hbabi, L.; Bourdy, G.; Deharo, E. Sacha Inchi oil (Plukenetia volubilis L.) effect on adherence of Staphylococus aureus to human skin explant and keratinocytes in vitro. J. Ethnopharmacol. 2015, 171, 330-334. [CrossRef] [PubMed]

8. Timilsena, Y.P.; Vongsvivut, J.; Tobin, M.J.; Adhikari, R.; Barrow, C.; Adhikari, B. Investigation of oil distribution in spray-dried chia seed oil microcapsules using synchrotron-FTIR microspectroscopy. Food Chem. 2019, 275, 457-466. [CrossRef] [PubMed]

9. Russo, P.; Zacco, R.; Rekkas, D.M.; Politis, S.; Garofalo, E.; Gaudio, P.; Aquino, R.P. Application of experimental design for the development of soft-capsules through a prilling, inverse gelation process. J. Drug Deliv. Sci. Technol. 2019, 49, 577-585. [CrossRef]

10. Donato, E.M.; Martins, L.A.; Fröehlich, P.E.; Bergold, A.M. Development and validation of dissolution test for lopinavir, a poorly water-soluble drug, in soft gel capsules, based on in vivo data. J. Pharm. Biomed. 2008, 47, 547-552. [CrossRef] [PubMed]

11. Silva, K.F.; Carvalho, A.G.; Rabelo, R.; Hubinger, M. Sacha inchi oil encapsulation: Emulsion and alginate beads characterization. Food Bioprod. Process. 2019, 116, 118-129. [CrossRef]

12. Chen, F.; Fan, G.; Zhang, Z.; Zhang, R.; Deng, Z.; McClements, D.J. Encapsulation of omega-3 fatty acids in nanoemulsions and microgels: Impact of delivery system type and protein addition on gastrointestinal fate. Int. Food Res. J. 2017, 100, 387-395. [CrossRef] [PubMed]

13. Rasti, B.; Erfanian, A.; Selamat, J. Novel nanoliposomal encapsulated omega-3 fatty acids and their applications in food. Food Chem. 2017, 230, 690-696. [CrossRef] [PubMed] 
14. Eratte, D.; McKnight, S.; Gengenbach, T.R.; Dowling, K.; Barrow, C.J.; Adhikari, B.P. Co-encapsulation and characterisation of omega-3 fatty acids and probiotic bacteria in whey protein isolate-gum Arabic complex coacervates. J. Funct. Foods 2015, 19, 882-892. [CrossRef]

15. Chen, R.; Guo, X.; Liu, X.; Cui, H.; Wang, R.; Han, J. Formulation and statistical optimization of gastric floating alginate/oil/chitosan capsules loading procyanidins: In vitro and in vivo evaluations. Int. J. Biol. Macromol. 2018, 108, 1082-1091. [CrossRef]

16. Hu, J.; Liu, S.; Deng, W. Dual responsive linalool capsules with high loading ratio for excellent antioxidant and antibacterial efficiency. Colloids Surf. B 2020, 190, 110978. [CrossRef]

17. Gullapalli, R.P.; Mazzitelli, C.L. Gelatin and Non-Gelatin Capsule Dosage Forms. J. Pharm. Sci. 2017, 106, 1453-1465. [CrossRef]

18. Gullapalli, R.P. Soft gelatin capsules (softgels). J. Pharm. Sci. 2010, 99, 4107-4148. [CrossRef]

19. Gómez-Mascaraque, L.G.; Soler, C.; López-Rubio, A. Stability and bioaccessibility of EGCG within edible micro-hydrogels. Chitosan vs. gelatin, a comparative study. Food Hydrocoll. 2016, 61, 128-138. [CrossRef]

20. Nawong, S.; Oonsivilai, R.; Boonkerd, N.; Truelstrup Hansen, L. Entrapment in food-grade transglutaminase cross-linked gelatin-maltodextrin microspheres protects Lactobacillus spp. during exposure to simulated gastro-intestinal juices. Int. Food Res. J. 2016, 85, 191-199. [CrossRef]

21. Camelo Caballero, L.R.; Wilches-Torres, A.; Cárdenas-Chaparro, A.; Gómez Castaño, J.A.; Otálora, M.C. Preparation and physicochemical characterization of softgels cross-linked with cactus mucilage extracted from cladodes of Opuntia Ficus-Indica. Molecules 2019, 24, 2531. [CrossRef] [PubMed]

22. Otálora, M.C.; Carriazo, J.G.; Iturriaga, L.; Nazareno, M.A.; Osorio, C. Microencapsulation of betalains obtained from cactus fruit (Opuntia ficus-indica) by spray drying using cactus cladode mucilage and maltodextrin as encapsulating agents. Food Chem. 2015, 187, 174-181. [CrossRef] [PubMed]

23. Otálora, M.C.; Carriazo, J.G.; Osorio, C.; Nazareno, M.A. Encapsulation of cactus (Opuntia megacantha) betaxanthins by ionic gelation and spray drying: A comparative study. Int. Food Res. J. 2018, 111, 423-430. [CrossRef] [PubMed]

24. Otálora, M.C.; Gómez Castaño, J.A.; Wilches-Torres, A. Preparation, study and characterization of complex coacervates formed between gelatin and cactus mucilage extracted from cladodes of Opuntia ficus-indica. LWT-Food Sci. Technol. 2019, 112, 108234. [CrossRef]

25. Shim, S.M.; Ferruzzi, M.G.; Kim, Y.-C.; Janle, E.M.; Santerre, C.R. Impact of phytochemical-rich foods on bioaccessibility of mercury from fish. Food Chem. 2009, 112, 46-50. [CrossRef]

26. Frutos, G.; Prior-Cabanillas, A.; París, R.; Quijada-Garrido, I. A novel controlled drug delivery system based on pH-responsive hydrogels included in soft gelatin capsules. Acta Biomater. 2010, 6, 4650-4656. [CrossRef]

27. Bernardes, A.L.; Moreira, J.A.; Tostes, M.D.G.V.; Costa, N.M.B.; Silva, P.I.; Costa, A.G.V. In vitro bioaccessibility of microencapsulated phenolic compounds of jussara (Euterpe edulis Martius) fruit and application in gelatine model-system. LWT Food Sci. Technol. 2019, 102, 173-180. [CrossRef]

28. Nieva-Echevarría, B.; Goicoechea, E.; Manzanos, M.J.; Guillén, M.D. 1H NMR and SPME-GC/MS study of hydrolysis, oxidation and other reactions occurring during in vitro digestion of non-oxidized and oxidized sunflower oil. Formation of hydroxy-octadecadienoates. Int. Food Res. J. 2017, 91, 171-182. [CrossRef]

29. Nieva-Echevarría, B.; Goicoechea, E.; Guillén, M.D. Behaviour of non-oxidized and oxidized flaxseed oils, as models of omega-3 rich lipids, during in vitro digestion. Occurrence of epoxidation reactions. Int. Food Res. J. 2017, 97, 104-115. [CrossRef]

30. Quinzio, C.; Corvalán, M.; López, B.; Iturriaga, L. Studying stability against coalescence in tuna mucilage emulsions. Acta Hortic. 2009, 811, 427-431. [CrossRef]

31. Pacheco, C.; González, E.; Robert, P.; Parada, J. Retention and pre-colon bioaccessibility of oleuropein in starchy food matrices, and the effect of microencapsulation by using inulin. J. Funct. Foods 2018, 41, 112-117. [CrossRef]

32. Gutiérrez, L.F.; Quiñones-Segura, Y.; Sanchez-Reinoso, Z.; Díaz, D.L.; Abril, J.I. Physicochemical properties of oils extracted from $\gamma$-irradiated Sacha Inchi (Plukenetia volubilis L.) seeds. Food Chem. 2017, 237, 581-587. [CrossRef] [PubMed]

33. Molendi-Coste, O.; Legry, V.; Leclercq, I.A. Why and How Meet n-3 PUFA Dietary Recommendations? Gastroent. Res. Pract. 2011,1-11. [CrossRef] [PubMed] 
34. Guillén, M.D.; Ruiz, A.; Cabo, N.; Chirinos, R.; Pascual, G. Characterization of sacha inchi (Plukenetia volubilis L.) oil by FTIR spectroscopy and H-1 NMR. Comparison with linseed oil. J. Am. Oil Chem. Soc. 2003, 80, 755-762. [CrossRef]

35. Simopoulos, A.P. The importance of the ratio of omega-6/omega-3 essential fatty acids. Biomed. Pharmacother. 2002, 56, 365-379. [CrossRef]

36. Yen, T.Y.; Stephen Inbaraj, B.; Chien, J.T.; Chen, B.H. Gas chromatography-mass spectrometry determination of conjugated linoleic acids and cholesterol oxides and their stability in a model system. Anal. Biochem. 2010, 400, 130-138. [CrossRef]

37. Nieva-Echevarría, B.; Goicoechea, E.; Guillén, M.D. Effect of adding alpha-tocopherol on the oxidation advance during in vitro gastrointestinal digestion of sunflower and flaxseed oils. Int. Food Res. J. 2019, 125, 108558. [CrossRef]

38. Tonon, R.V.; Pedro, R.B.; Grosso, C.R.; Hubinger, M.D. Microencapsulation of flaxseed oil by spray drying: Effect of oil load and type of wall material. Dry. Technol. 2012, 30, 1491-1501. [CrossRef]

39. Alpizar-Reyes, E.; Varela-Guerrero, V.; Cruz-Olivares, J.; Carrillo-Navas, H.; Alvarez-Ramirez, J.; Pérez-Alonso, C. Microencapsulation of sesame seed oil by tamarind seed mucilage. Int. J. Biol. Macromol. 2020, 145, 207-215. [CrossRef]

40. Silva Soares, B.; Pinto Siqueira, R.; de Carvalho, M.G.; Vicente, J.; Garcia-Rojas, E.E. Microencapsulation of sacha inchi oil (Plukenetia volubilis L.) using complex coacervation: Formation and structural characterization. Food Chem. 2019, 298, 125045. [CrossRef] [PubMed]

41. Maderuelo, C.; Zarzuelo, A.; Lanao, J.M. Critical factors in the release of drugs from sustained release hydrophilic matrices. J. Control. Release 2011, 154, 2-19. [CrossRef] [PubMed]

42. Jannasari, N.; Fathi, M.; Moshtaghian, S.J.; Abbaspourrad, A. Microencapsulation of vitamin D using gelatin and cress seed mucilage: Production, characterization and in vivo study. Int. J. Biol. Macromol. 2019, 129, 972-979. [CrossRef] [PubMed]

43. Cortés-Camargo, S.; Acuña-Avila, P.E.; Rodríguez-Huezo, M.E.; Román-Guerrero, A.; Varela-Guerrero, V.; Pérez-Alonso, C. Effect of chia mucilage addition on oxidation and release kinetics of lemon essential oil microencapsulated using mesquite gum-Chia mucilage mixtures. Int. Food Res. J. 2019, 116, 1010-1019. [CrossRef]

44. Papillo, V.A.; Arlorio, M.; Locatelli, M.; Fuso, L.; Pellegrini, N.; Fogliano, V. In vitro evaluation of gastro-intestinal digestion and colonic biotransformation of curcuminoids considering different formulations and food matrices. J. Funct. Foods 2019, 59, 156-163. [CrossRef]

45. Da Silva Stefani, F.; de Campo, C.; Paese, K.; Stanisçuaski Guterres, S.; Haas Costad, T.M.; Hickmann Flôres, S. Nanoencapsulation of linseed oil with chia mucilage as structuring material: Characterization, stability and enrichment of orange juice. Int. Food Res. J. 2019, 120, 872-879. [CrossRef]

46. Barrow, C.J.; Nolan, C.; Jin, Y. Stabilization of highly unsaturated fatty acids and delivery into foods. Lipid Technol. 2008, 19, 108-111. [CrossRef]

(C) 2020 by the authors. Licensee MDPI, Basel, Switzerland. This article is an open access article distributed under the terms and conditions of the Creative Commons Attribution (CC BY) license (http://creativecommons.org/licenses/by/4.0/). 